\title{
Animal models of ulcerative colitis and their application in drug research
}

This article was published in the following Dove Press journal:

Drug Design, Development and Therapy

II November 2013

Number of times this article has been viewed

\author{
Daren Low' \\ Deanna D Nguyen ${ }^{1,2}$ \\ Emiko Mizoguchi ${ }^{1,2}$ \\ 'Gastrointestinal Unit, Department \\ of Medicine, ${ }^{2}$ Center for the Study \\ of Inflammatory Bowel Disease, \\ Massachusetts General Hospital \\ and Harvard Medical School, \\ Boston, MA, USA
}

\begin{abstract}
The specific pathogenesis underlying inflammatory bowel disease is complex, and it is even more difficult to decipher the pathophysiology to explain for the similarities and differences between two of its major subtypes, Crohn's disease and ulcerative colitis (UC). Animal models are indispensable to pry into mechanistic details that will facilitate better preclinical drug/therapy design to target specific components involved in the disease pathogenesis. This review focuses on common animal models that are particularly useful for the study of UC and its therapeutic strategy. Recent reports of the latest compounds, therapeutic strategies, and approaches tested on UC animal models are also discussed.
\end{abstract}

Keywords: inflammatory bowel disease, preclinical trials, emerging therapy

\section{Introduction to ulcerative colitis}

Ulcerative colitis (UC) is an idiopathic chronic relapsing-remitting inflammatory disorder that affects the colon, characterized by diarrhea and rectal bleeding (Figure 1). The molecular etiology of UC development is complex and involves genetic, microbial, environmental, and other unknown factors (Figure 1). In this review, we discuss the underlying pathophysiology of UC and how observations from animal models that mimic UC contribute to better understanding of this disease and lead to advancement in novel treatment design.

Based on recent reports, there is a steady increase in the global incidence of UC. Currently, the prevalence in Europe and North America is 24.3 and 19.2 per 100,000 individuals, respectively, and 6.3 per 100,000 people in Asia and the Middle East. ${ }^{1}$ Most patients develop UC between the ages of 15 and 30 years, although individuals aged 50-70 years form another potential risk group. ${ }^{2}$ There are no significant differences in UC risk between sexes. The growing prevalence of this disease increases both economic and health care burdens. In the United States, an individual UC patient has an average annual expenditure of approximately $\$ 15,020$ in medical costs. ${ }^{3}$ Thus, better and more affordable treatments and eventually a cure are greatly needed.

An individual's genetic makeup forms one of the primary causal factors for inflammatory bowel disease (IBD) development. The first clue that there is a partial genetic component to the risk of IBD comes from the observation that a family history of IBD confers one with a higher probability of disease development. The offspring of IBD-affected mothers have a higher incidence of developing the disease as compared with the offspring of IBD-affected fathers, indicating that maternal inheritance factors predetermine UC-related genetic risk. ${ }^{4}$ Molecular studies have also shown evidence of
Correspondence: Emiko Mizoguchi Massachusetts General Hospital, GRJ 825D, 55 Fruit Street, Boston, MA 02114, USA

Tel +l 6177267892

Fax $+1617726-3673$

Email emizoguchi@partners.org 


\section{Ulcerative colitis}

\section{Features}

Causal

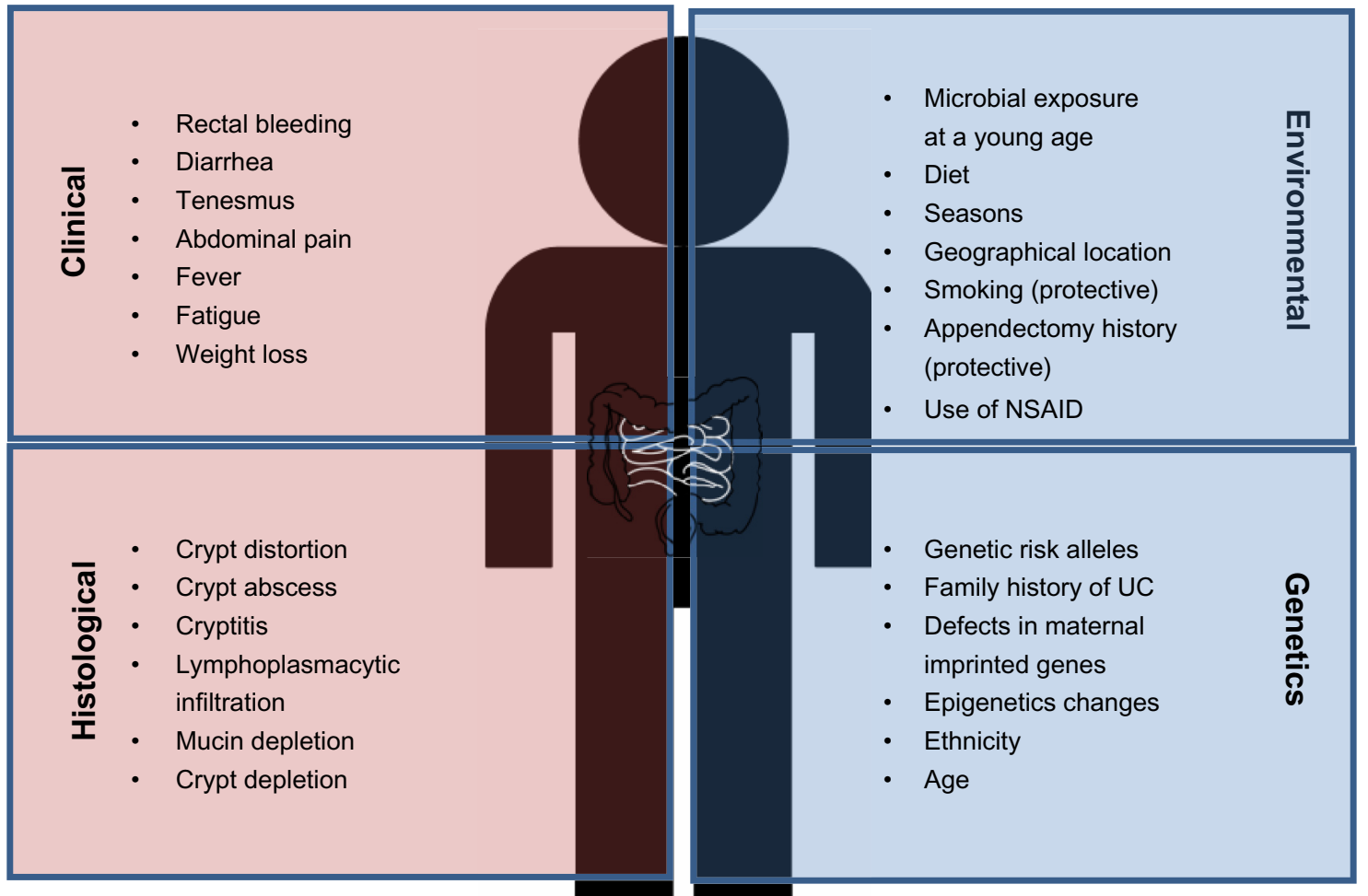

Figure I Clinical and histological features of ulcerative colitis (UC) and causal factors influencing UC risk. Common diagnostic criteria of UC include both clinical and histological features. The main causes of UC are individual genetic background as well as environmental factors, which may alter/synergize with the genetic/epigenetic makeup.

Abbreviations: UC, ulcerative colitis; NSAID, nonsteroidal anti-inflammatory drug.

UC-associated genetic imprinting, such that maternal inherited gene expression and functions have been directly linked to IBD development. ${ }^{5}$ Recent Genome-Wide Association Studies have also identified 47 UC risk alleles. ${ }^{6}$ In addition to direct DNA sequence variants, changes in epigenetics, including DNA methylation, histone modifications, and noncoding RNA, contribute an additional layer of genetic contribution to IBD risk.

Environment and lifestyle constitute the second major arm of UC causal factors. During infancy, early exposure to microbes protects individuals from UC development at subsequent life stages. This is in sync with the notion that improved sanitation in developed countries may lead to immaturity of an individual's immune system during childhood and subsequently increase susceptibility to UC later in life. Seasonal changes also exacerbate UC conditions, such that symptoms occur more frequently during spring and summer seasons. ${ }^{7}$ Meta-analysis has shown that smokers tend to be protected from UC as compared with nonsmokers. ${ }^{8}$ In contrast to UC, smoking appears to worsen Crohn's disease (CD) symptoms. ${ }^{9}$
With the identification of these fundamental causal factors, the next step is to prioritize the directions for the next wave of UC research. The Crohn's and Colitis Foundation of America composed a list of priorities for IBD research agendas, with the ultimate goal of applying bench-side discoveries to the bedside. ${ }^{10}$ To facilitate understanding of UC pathogenesis, animal models, particularly mouse models, have become indispensable tools to study this topic (Figure 2). Experimental colitis can be induced using chemical irritant or bacterial infection. Over the years, many transgenic ( $\mathrm{Tg})$ and gene knockout (KO) mouse strains have been developed, allowing the opportunity to address specific pathophysiologic questions related to UC and to test novel drug/therapeutic candidates pertinent to specific components/pathways.

\section{Chemical and bacterial induction of colitis in animal models}

A UC-like phenotype can be induced in animals easily using either chemical administration or bacterial infection. Although the majority of these reports were performed on mice, chemically induced colitis has also been tested on other 


\section{Mouse IBD models}

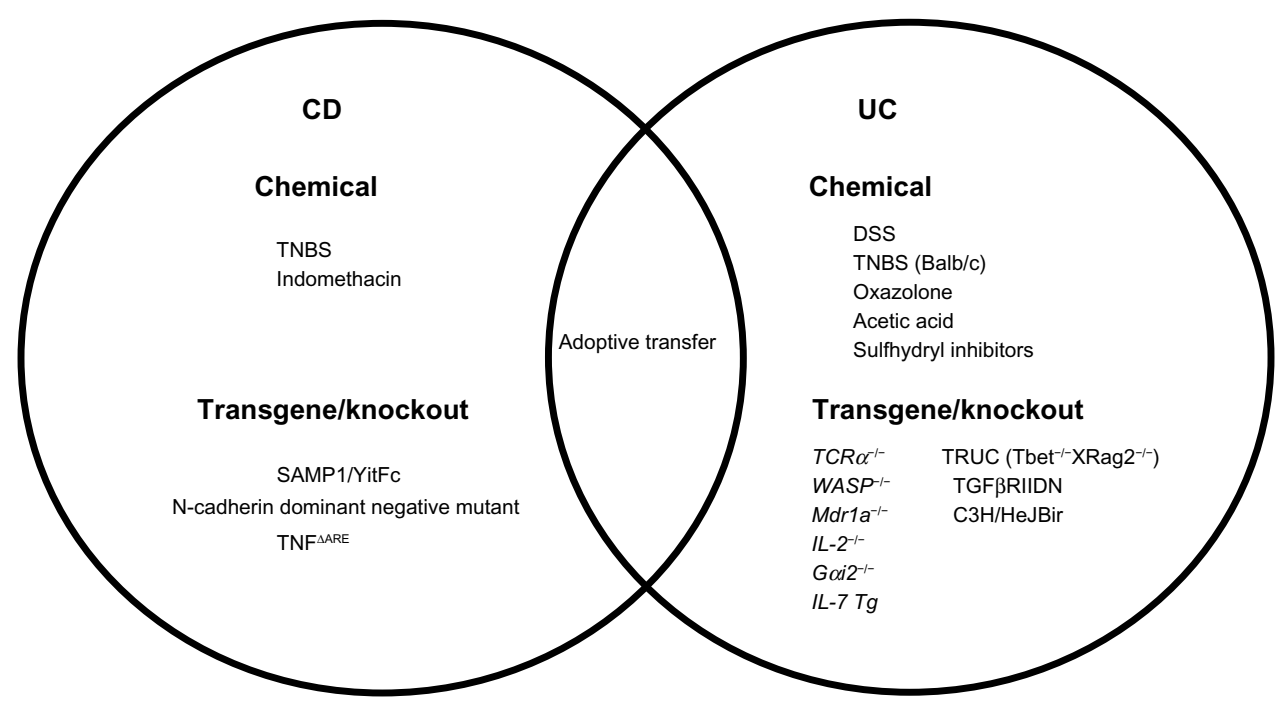

Figure 2 Mouse models of inflammatory bowel disease (IBD). Many mouse models are currently available that mimic the two major subtypes of IBD (Crohn's disease [CD] and ulcerative colitis [UC]). Specific mouse models with characteristics of CD and/or UC are summarized.

Abbreviations: $\triangle \mathrm{ARE}$, a deletion nutant in AU-rich elements; DSS, dextran sulfate sodium; Goi2, guanine nucleotide-binding protein $\mathrm{G}(\mathrm{i})$ subunit $\alpha-2$; IL, interleukin; Mdrla, multiple drug resistance Ia; TCR, T-cell receptor; Tg, transgenic; TNBS, 2,4,6-trinitrobenzenesulfonic acid; TNF, tumor necrosis factor; TRUC, T-bet(-I-)RAG2(-I-) ulcerative colitis; WASP, Wiskott-Aldrich syndrome protein; TGF, transforming growth factor.

species, ranging from lower organisms such as zebrafish and drosophila to higher organisms, including rats and porcine. The choice of animal and induction method will depend on the specific question the particular study is addressing.

\section{Dextran sulfate sodium-induced colitis}

A common method to create ulcer formation and inflammation is through administration of dextran sulfate sodium (DSS) to animals. Strictly speaking, DSS does not directly cause intestinal inflammation per se; rather, it exerts chemical injury to the intestinal epithelium, resulting in exposure of the lamina propria (LP) and submucosal compartment to luminal antigens and enteric bacteria, triggering inflammation. The effectiveness of DSS-induced colitis depends on several factors, including dosage (usually $1 \%-5 \%$ ), duration (acute or chronic), manufacturer/batch of DSS, strain of animals $(\mathrm{C} 3 \mathrm{H} / \mathrm{HeJ}$ and Balb/c mice strains are more susceptible), sex of animals (male mice are more susceptible), and microbial environment of animals (eg, germ-free [GF] versus specific pathogen-free $[\mathrm{SPF}])$. In addition, DSS-administered mice also show highly variable disease severity. Unless animals are treated with multiple pulses of DSS, the phenotype lacks the chronic changes observed in humans. Nevertheless, DSSinduced colitis is still commonly used, given its simplicity to administer (usually in the drinking water) and the ease of controlling the dosage (to determine severity) and duration (to study the inflammatory or recovery process). Although the earliest change in this model is characterized by a progressive disruption of colonic crypts, macrophages and cluster of differentiation $4\left(\mathrm{CD}^{+}\right) \mathrm{T}$ cells become more prominent in areas of wound healing in the basal portion of the LP after the late recovery phase. ${ }^{11}$ Many chemical compounds, gene/ cell therapy, and microbial interventions have been reported to be therapeutically effective in DSS-induced colitis (see review by Mizoguchi ${ }^{12}$ ).

\section{Oxazolone colitis}

Intrarectal administration of the hapten oxazolone with ethanol into murine animals results in acute colitis. The condition is characterized by a T helper (Th)2-type immune response with a marked increase in interleukin (IL)-4 and IL-5 production, accompanied by body weight loss, diarrhea, ulcers, and loss of epithelial cells in the large intestine. ${ }^{13}$ Thus, it resembles UC rather than other IBD subtypes, distinguishing it from trinitrobenzene sulfonic acid (TNBS)-induced colitis (Th1-mediated immune responses), which mimics CD more closely. Natural killer T cells and their associated cytokine, mainly IL-13, are also intimately involved in oxazolone-induced colitis induction. ${ }^{14}$ Many studies have utilized oxazolone-induced colitis to test disease pathology and therapeutic interventions for UC. ${ }^{15,16}$ It was recently shown in oxazolone-treated mice that nicotine upregulates 
the nicotine acetylcholine receptors on $\mathrm{CD}^{+} \mathrm{T}$ cells and increases regulatory $\mathrm{T}$ cell (Treg) numbers, accompanied by a decrease in the number of Th17 cells, resulting in the amelioration of the inflammatory phenotype. ${ }^{16}$ In contrast, nicotine treatment in TNBS-induced mice, which have CD-like Th1-associated inflammation, upregulates Th17 cell numbers associated with an exacerbation of the inflammatory response. In a separate study, mice treated with 3-hydroxy-3-methylglutaryl coenzyme A reductase inhibitor showed suppression of the Th1 response and attenuation of intestinal inflammation in TNBS-induced colitis, but not oxazolone-induced colitis. ${ }^{15}$ These examples illustrate the importance of choosing an appropriate model to answer a specific question when exploring a therapeutic potential of a drug/compound for a particular disease.

\section{Acetic acid-induced colitis}

Intrarectal administration of diluted acetic acid provides an alternative method to create chemical injury to the mucosal epithelium that induces a transient phenotype mimicking UC. The first report of this model was demonstrated by MacPherson and Pfeiffer ${ }^{17}$ where they instilled 10\%-50\% acetic acid into the rat rectum for 10 seconds, followed by flushing the lumen with saline three times. A diffuse colitis in an acetic acid dose-dependent manner was observed in these rats, with histopathological features including ulceration of the distal colon and crypt abnormalities. ${ }^{17}$ The ulcerated and injured mucosa, with destruction sometimes extending to the LP, begins to heal within days in mice and a few weeks later in rats. ${ }^{18}$ Subsequent modifications and optimization over years focused on varying the concentration of acetic acid and the contact time. As enemas of high concentration of acetic acid into the lumen often cause perforations, the latest protocol is executed using 4\% acetic acid with 15-30 seconds of exposure. The advantages of acetic acid-induced colitis are its low cost and the ease of administration.

There are a large number of reports that describe compounds that can ameliorate acetic acid-induced colitis. These include compounds aiming to target reactive oxidative species such as $\mathrm{N}$-acetyl cysteine, trimetazidine, vitamin $\mathrm{E}$, and melatonin, suggesting that acetic acid-induced colitis may be a good model to study the efficacy of drugs that aim to interfere with reactive oxidative species pathogenesis. ${ }^{19-22} \mathrm{Of}$ note, the epithelial injury observed within the first 24 hours of acetic acid induction is not immunologic in nature. Thus, designing drugs that target immune responses should be tested at a time point after 24 hours postinduction.

\section{Salmonella-induced colitis}

The gram-negative Salmonella typhimurium and Salmonella dublin are food-borne enteric bacterial pathogens that can cause intestinal diseases. Direct oral infection of $S$. typhimurium into mice results in systemic infection that may mask the phenotype of intestinal inflammation. However, this problem can be overcome by pretreating mice with an oral antibiotic cocktail to disrupt commensal microbial flora and allow better colonization of $S$. typhimurium, resulting in high-density growth of the bacterium within a day. The initial inflammation caused by such colonization has similar histopathological characteristics to human UC, including epithelial crypt loss, erosion, and neutrophilic infiltration. Of note, this mode of colitis induction usually results in systemic infection within 5-7 days of infection. Therefore, it is perceived that $S$. typhimurium infection is a valuable model to study the acute phase, but not later stages, of colitis.

Salmonella has been shown to function as a good vector to introduce certain gene components into the mucosa to elicit immune response for vaccines against colitis. ${ }^{23}$ It can efficiently invade into the intestinal epithelium and Peyer's patches (PP). Therefore, careful and detailed characterization of its virulence factors is critical to efficiently create a safe attenuated strain for such gene therapy vaccination. Vaccinating mice with an attenuated mutant $S$. typhimurium strain that contains deletion of the znuABC operon, which encodes a zinc importer responsible for metal recruitment in the infected host, elicits effective immune responses and protects mice from subsequent Salmonella infection. ${ }^{23}$ In addition, elucidating how $S$. typhimurium interacts with host epithelial cells facilitates further understanding of ways to potentially prevent UC onset. For instance, blocking host inflammatory-induced proteins (eg, chitinase 3-like 1 [CHI3L1, also known as YKL-40]) in the colon using appropriate antibodies (Abs) or inhibitors can prevent colonization of S. typhimurium on the intestinal epithelium, thus preventing further invasion. ${ }^{24}$

\section{Adherent-invasive E. coli}

The commensal adherent-invasive Escherichia coli (AIEC) strain was originally isolated from the ileum of CD patients and was shown to exacerbate intestinal inflammation in an opportunistic manner. ${ }^{25}$ However, AIEC can adhere to both small and large intestinal epithelial cells (IECs) with equal affinity. ${ }^{26}$ Induction of colonic inflammation in animal models using AIEC infection requires mild epithelial damage, such as low-dose DSS treatment, during the entire course of the infection. The phenotype of the colonic inflammation 
mimics UC, including body weight loss, presence of blood in stool, and colonic neutrophilic infiltrations. ${ }^{24} \mathrm{~A}$ recent study showed that AIEC encodes a pathogenic form of chitinase, chiA, that is distinguishable from other nonpathogenic $E$. coli and is utilized to adhere to host epithelial cells by binding with colonic inducible protein $\mathrm{CHI} 3 \mathrm{~L} 1 .{ }^{27}$ Administration of chitin microparticles (1-10 $\mu \mathrm{m}$ in size) into mice ameliorates colonic intestinal inflammation, presumably by blocking the interaction of bacterial-derived factors (such as AIEC chiA) with host CHI3L1. ${ }^{28}$ Similarly, using anti-CHI3L1 Abs also resulted in an ameliorative effect. ${ }^{24}$

Effective invasion into, and colonization of, AIEC in the mucosal epithelium is usually hindered by mucosal biofilm formation of probiotic bacteria, such as Lactobacillus casei. ${ }^{29}$ Certain antibiotics result in the disruption of the intestinal microflora, including the probiotic biofilm, creating an ideal environment for the opportunistic AIEC to adhere to and invade IECs and macrophages. It has been shown that AIEC does not adhere efficiently in non-antibiotic-treated mice, but colonizes well in the antibiotic-treated animals. ${ }^{30}$ This result suggests that restoration of a beneficial microbiota, either through probiotic intake or other methods such as fecal microbial transplantation, can theoretically prevent further exacerbation of intestinal inflammation by commensal pathogenic bacteria.

\section{Transgenic and gene knockout animal models of ulcerative colitis IL-7Tg mice}

IL-7 is a pleiotropic cytokine and a candidate risk gene associated with UC. IECs express IL-7, which serves as a regulatory factor for the development and homeostasis of lymphocytes that express IL-7 receptor (IL-7R). ${ }^{31}$ In UC patients, IL-7 protein expression is significantly upregulated and exerts its optimal effects in maintaining long-lived memory $\mathrm{CD}^{+}{ }^{+} \mathrm{T}$ cells in colonic mucosa. ${ }^{32} \mathrm{IL}-7$ appears to mediate the persistence of chronic colitis through the IL-7R $\alpha$ chain expressed specifically on $\mathrm{CD} 4^{+} \mathrm{T}$ cells, but not on other cell types. ${ }^{33}$ Thus, blocking IL-7R functions has shown to be effective in suppressing adoptive transfer-induced intestinal inflammation in mice. ${ }^{34}$ Administration of specific anti-IL-7R Ab into murine colitis models (eg, Helicobacter bilis-infected Mdr1 KO mice) also controls macrophage and dendritic cell (DC) expansion. ${ }^{35}$

$I L-7 \mathrm{Tg}$ mice expressing the murine IL-7 complementary DNA spontaneously develop acute colitis at 1-3 weeks of age, characterized by a mixed cellular infiltration that includes neutrophils and lymphocytes. ${ }^{36}$ At 8-12 weeks of age, the Tg mice display rectal prolapse and remittent intestinal bleeding, with rectal erosion, goblet cell loss, and occasional crypt abscesses. Upregulation of IL-7R on mucosal lymphocytes is also associated with disease progression. ${ }^{36}$ Thus, an IL-7 Tg mouse model is useful to understand T-cell-mediated pathogenesis of colitis for therapeutic interventions targeting T-cell functions.

\section{TCR $\alpha$ KO mice}

In 1993, Mombaerts et $\mathrm{al}^{37}$ showed that T-cell receptor $\alpha$ chain $(T C R \alpha) \mathrm{KO}$ mice spontaneously developed chronic colitis, which was mediated by a Th2-type immune response closely resembling human $\mathrm{UC}$ with an inflammatory pattern restricted primarily to the colonic mucosa. At 4-6 months of age, approximately $60 \%$ of $T C R \alpha \mathrm{KO}$ mice produced soft stools, associated with loss of goblet cells, and a mixed cellular infiltration mainly consisting of lymphocytes and neutrophils in the affected LP. Spontaneous colitis develops in TCR $\alpha \mathrm{KO}$ animals when raised in a helicobacter-free/SPF facility, but not in GF or conventional (CV) environments. ${ }^{38}$ When SPF-born TCR $\alpha$ KO mice were subsequently transferred into a $\mathrm{CV}$ environment, the mice developed attenuated mild colitis. ${ }^{39}$ This supports the notion that early life exposure to environmental microbes may be protective against colitis risk later in life.

Several therapeutic interventions have been tested in TCR $\alpha \mathrm{KO}$ mice with efficacy. Daily oral administration of $3 \mathrm{mg} / \mathrm{kg}$ dexamethasone, a member of the glucocorticoid class of steroid drugs, into TCR $\alpha \mathrm{KO}$ mice was effective in preventing goblet cell loss and leukocyte infiltration. ${ }^{40}$ Immunotherapy treatment using anti-IL-4 Abs has also been shown to suppress both clinical and histological signs of colitis by controlling Th2-type cytokine productions. ${ }^{41}$ Administration of purified immunoglobulin $G$, with a mixture of monoclonal auto-Abs reactive against colonic epithelial cells, can attenuate colitis in B-cell-deficient TCR $\alpha \mathrm{KO}$ mice. ${ }^{42}$ Carbon monoxide, a prominent component in cigarette smoking, exerts anti-inflammatory effects in TCR $\alpha \mathrm{KO}$ mice through suppression of IL-1 $\beta$, tumor necrosis factor- $\alpha$ (TNF $\alpha)$ and IL-4, as well as through induction of IL-10 production, providing molecular insights into how smoking has protections against $\mathrm{UC}{ }^{43}$ In addition, oral administration of chitin microparticles into $T C R \alpha \mathrm{KO}$ colitic mice also showed suppression of IL-4 and TNF $\alpha$ production and increased interferon- $\gamma$ (IFN $\gamma$ ) production in the mesenteric lymph nodes (MLNs). ${ }^{28}$ It was found that chitin treatment in TCR $\alpha \mathrm{KO}$ mice normalizes intestinal bacterial composition, as compared with 
control groups that exhibit expansion of a certain genre of commensals microbes.

\section{Wiskott-Aldrich syndrome protein $\mathrm{KO}$ mice}

Patients with Wiskott-Aldrich syndrome have not only immunodeficiency but also often autoimmune manifestations, with $5 \%-10 \%$ of patients developing colonic inflammation. ${ }^{44,45}$ They either lack or express a defective form of Wiskott-Aldrich syndrome protein (WASP), an intracellular molecule specific to hematopoietic cells. Given the major biological role of WASP in actin polymerization, it is crucial for multiple cellular functions such as cell motility, activation, and signaling. ${ }^{46}$ Like their human counterpart, WASP KO mice on the $129 \mathrm{SvEv}$ background also develop spontaneous colitis from 4 months of age. Full penetrance was observed at 6 months of age. The pancolitic pattern of inflammation along with elevations in Th2 cytokines in the colonic LP associated with this model mirror features of UC. ${ }^{47}$ Initially, it was hypothesized that aberrantly activated effector $\mathrm{T}$ cells as well as deficient and dysfunctional Tregs associated with WASP deficiency bore the sole responsibility for colitis development, but more recent studies have revealed a role of WASP KO innate immune cells in disrupting mucosal regulation..$^{47,48}$ The advantages of using this model for studying UC pathogenesis are the Th2-skewed cytokine profile mimicking human disease, aberrant natural Treg and innate immune cell function, and a human correlate where a subset of patients with the same genetic defect also suffer from colitis.

Several treatment strategies have been investigated using WASP KO animals. WASP-expressing retrovirus was transduced into WASP-deficient hematopoietic stem cells before transfer into lethally irradiated recipient mice, resulting in the attenuation of colitis along with normalized populations of mature B and T cells compared with chimeric mice with control retrovirus-transduced WASP-deficient bone marrow cells that developed disease. ${ }^{49}$ In addition, given that UC patients were found to produce lower levels of intestinal alkaline phosphatase, WASP KO mice were treated with oral intestinal alkaline phosphatase and were found to effectively attenuate colitis with less cellular infiltration and reduced production of IL-4 and IFN $\gamma^{50,51}$ Furthermore, direct neutralization of IL-4, but not IFN $\gamma$, with weekly injection of anti-IL-4 antibody for 8 weeks ameliorated disease. ${ }^{47}$ Lastly, administration of a newly formulated IL-10-immunoglobulin fusion protein completely abrogated colitis development in chimeric mice with WASP-deficient innate immune cells. ${ }^{48}$

\section{Mdrla KO mice}

Mdrla KO mice lack the multiple drug resistance 1a (mdr1a) gene, encoding for the cell surface P-glycoprotein (P-gp) transporter that pumps small amphiphilic/hydrophobic molecules across the cell membrane. Approximately $25 \%$ of these mice develop colitis between 8 and 36 weeks of age when raised in an SPF facility, but not in a GF facility. ${ }^{52}$ Histological findings in this model include mucosal thickening and loss of goblet cells that is also accompanied by crypt abscesses and ulceration in the colon. ${ }^{52} \mathrm{Mdrla}$ KO mice are devoid of the proper ability to dispose of bacterial breakdown products in epithelial cells. The accumulation of these bacterial products increases excess/abnormal antigen presentation to neighboring $\mathrm{T}$ cells, leading to a marked T-cell activation state that drives the colitis. Recently, T-cell involvement in the development of colitis in the Mdrla KO model has been increasingly characterized. The lack of Mdrla (P-gp) restricts the development of inducible Treg cells, thus producing fewer functional forkhead box P3 (Foxp3)-positive Treg cells and therefore less IL-10 production to control and regulate intestinal inflammation. ${ }^{53}$ Hematopoietic-specific Mdrla deficiency results in a more severe colitis than mice that have Mdrla deficiency only in IECs, suggesting a critical role of immune cell-derived P-gp in colitis development. ${ }^{54}$

Consistent with the finding that Mdrla KO mice in a GF facility do not develop colitis, prophylactic treatment using broad-spectrum oral antibiotics greatly reduces the incidence of colitis development. ${ }^{52} \mathrm{Mdrla}$ KO mice fed with a diet containing a polyphenol compound called curcumin (commonly found in spices used in Asian food) demonstrated upregulation of xenobiotic metabolism as well as downregulation of proinflammatory pathways and associated attenuation of histological signs of colitis. ${ }^{55}$ Meta-analysis has identified several polymorphisms in the Mdrla locus in human $\mathrm{UC}$, but not $\mathrm{CD}$, patients that affect its gene expression and regulation. ${ }^{56}$ Loss of Mdrla expression was implicated in $\mathrm{UC}$ development, but not in CD patients. ${ }^{57}$ Administration of the probiotics Lactobacilli upregulates P-gp expression under both normal and inflammatory conditions, and reduces myeloperoxidase activity and histological signs of injury in DSS-treated mice. ${ }^{58}$ These results suggest that Mdrla KO mice can be utilized in the design of drugs targeting intestinal epithelial barrier dysfunction and in elucidating the mechanisms underlying the benefits of probiotic treatment.

\section{IL-2 KO mice}

IL-2 is an effective regulatory cytokine produced by $\mathrm{CD} 4^{+}$ $\mathrm{T}$ cells and amplifies stimulatory responses by promoting 
$\mathrm{T}$ lymphocyte expansion. $I L-2 \mathrm{KO}$ mice are viable and develop normally before 4 weeks of age, thereafter displaying $50 \%$ mortality. The remaining mice develop colon-restricted inflammation with $100 \%$ penetrance by 6 weeks of age when maintained in a CV environment, but not in GF conditions. ${ }^{59}$ The clinical and histological characteristic of this inflammation bears striking resemblance to human UC, including crypt abscess, ulcerations, and loss of goblet cells..$^{59}$ Of note, GF-reared $I L-2 \mathrm{KO}$ mice showed signs of other non-UC phenotypes such as disturbances in bone marrow hematopoietic cells, lymphocytic hyperplasia, hemolytic anemia, and generalized autoimmunity, but not colitis. SPF-maintained mice begin to show signs of colonic inflammation only at 17-20 weeks of age, and heightened T-cell and B-cell activation were found to mediate the colitis. ${ }^{59}$ These $\mathrm{T}$ cells are presumably activated through altered antigen presentation by DCs. In $I L-2 \mathrm{KO}$ mice, colonic DCs increase four- to five-fold under inflammatory conditions and localize within the T- and B-cell aggregates, expressing high levels of major histocompatibility complex class II, CD80, CD86, CD40, CD205, and C-C chemokine receptor type 5 molecules. ${ }^{60}$ These changes in DC phenotype may be induced by certain colitogenic bacteria or antigens. It was shown that Bacteroides vulgatus mpk monocolonized $I L-2 \mathrm{KO}$ mice do not manifest colitis but instead exert protective effect, unlike $E$. coli mpk monocolonized $I L-2$ KO mice that develop disease. ${ }^{61,62}$ Bacteroides vulgatus mpk-infected $I L-2 \mathrm{KO}$ mice increase IL-6 expression and semimaturation of LP DCs. ${ }^{62}$ It was reported that intestinal bacterial flora and endogenous antigens, but not environmental antigens, are the main contributors affecting SPF-associated colitis phenotype in this murine model. ${ }^{63}$

Specific targets have been identified to control the severity of colitis in IL-2 KO mice. It was noted that 2,4,6-trinitrophenolovalbumin-immunized $I L-2 \mathrm{KO}$ mice displayed much more severe intestinal inflammation as compared with untreated mice. In contrast, mice administrated monoclonal Abs against the $\alpha E \beta 7$ integrin together with 2,4,6-trinitrophenol-ovalbumin immunization demonstrated attenuated disease associated with a reduction in $\mathrm{CD}^{+}$cells and IFN $\gamma$ production in the $\mathrm{LP}^{64} \mathrm{In}$ addition, treating 8-week-old $I L-2 \mathrm{KO}$ mice with green tea polyphenol extract in the drinking water reduced IFN $\gamma$ and TNF $\alpha$ production after 1 week of treatment and displayed further improvement in the general histological scores of the spontaneous colitis after 6 weeks. ${ }^{65}$

\section{Goi2 KO mice}

Guanine nucleotide-binding protein $\mathrm{G}(\mathrm{i})$ subunit $\alpha$-2 (Goi2) $\mathrm{KO}$ mice exhibit distinct lethal diffuse colitis phenotype within 5-7 weeks of age, associated with clinical and histopathological features resembling UC. ${ }^{66}$ These include colonic thickening, lymphocyte and neutrophilic infiltrations, crypt and goblet loss, and crypt abscesses. Cell analysis also showed a marked increase in memory CD44 $4^{\text {high }}, \mathrm{CD} 45 \mathrm{RB}^{\text {low }}$, and $\mathrm{CD} 62 \mathrm{~L}^{\text {low }} \mathrm{CD}^{+}{ }^{+} \mathrm{T}$ cells in $\mathrm{LP}^{67}$ Transfer of Goi2 $\mathrm{KO}$ splenic $\mathrm{CD}^{+} \mathrm{T}$ cells, but not MLN $\mathrm{CD}^{+} \mathrm{T}$ cells, into immunodeficient mice causes severe colitis. ${ }^{68} \mathrm{~B}$ cells within the hematopoietic compartment appear to be an important regulatory factor in controlling the colitis phenotype in Goi2 KO mice, as indicated by a reduction in LPS-induced proliferation and IL-10 production. ${ }^{69}$ Indeed, cell transfer of B cells isolated from wild-type MLNs can protect Goi2 KO mice from colitis.

Testing of therapeutic agents in Goi2 KO mice has shown positive results in ameliorating colitis. Intraperitoneal injection of the acellular Bordetella pertussis vaccine into Goi 2 KO mice demonstrated an increase in regulatory IL-10 production in the intestine, accompanied by a significant reduction in colitis. ${ }^{70}$ Excessive proliferation of $\mathrm{CD} 4{ }^{+} \mathrm{T}$ cells was controlled upon treatment, along with an increase in apoptosis of activated Th1-type $\mathrm{CD}^{+} \mathrm{T}$ cells. Ex vivo cultures of colons obtained from Goi2 $\mathrm{KO}$ mice respond to the anti-inflammatory agent methyl-prednisolone in a similar manner as colons from mice that had been orally treated with the same drug, as determined by inflammatory-associated gene expression. ${ }^{71}$ Hence, colonic culture systems, rather than in vivo testing, can be utilized to validate future IBD therapies.

\section{Comparative evaluation of various animal ulcerative colitis models in drug development}

With the current spectrum of animal models available to study UC, together with the explosive information of the underlying molecular pathogenesis of the disease, these resources can be carefully leveraged to determine the best approaches to design therapeutic drug targets to combat the disease (Figure 3).

The most obvious dogma is to start testing using lower organism models, including Caenorhabditis elegans, drosophila, and zebrafish, that provide a convenient and fast approach to doing large-scale screenings of both drugs and genetic targets (see review by Lin and Hackam ${ }^{72}$ ). These lower organisms are ideal subjects to study microbial response, as well as understanding the genetics of signaling pathway or intestinal physiology. Upon identifying drug candidates or genetic targets from pilot tests in lower 


\section{Environmental/bacterial flora}

C. elegans

Zebrafish

Mouse (husbandry)
Bacterial virulence factors

Salmonella infection

AIEC infection
Host-microbial interaction

Salmonella infection

AIEC infection

Chemically induced colitis

(DSS, oxazolone)

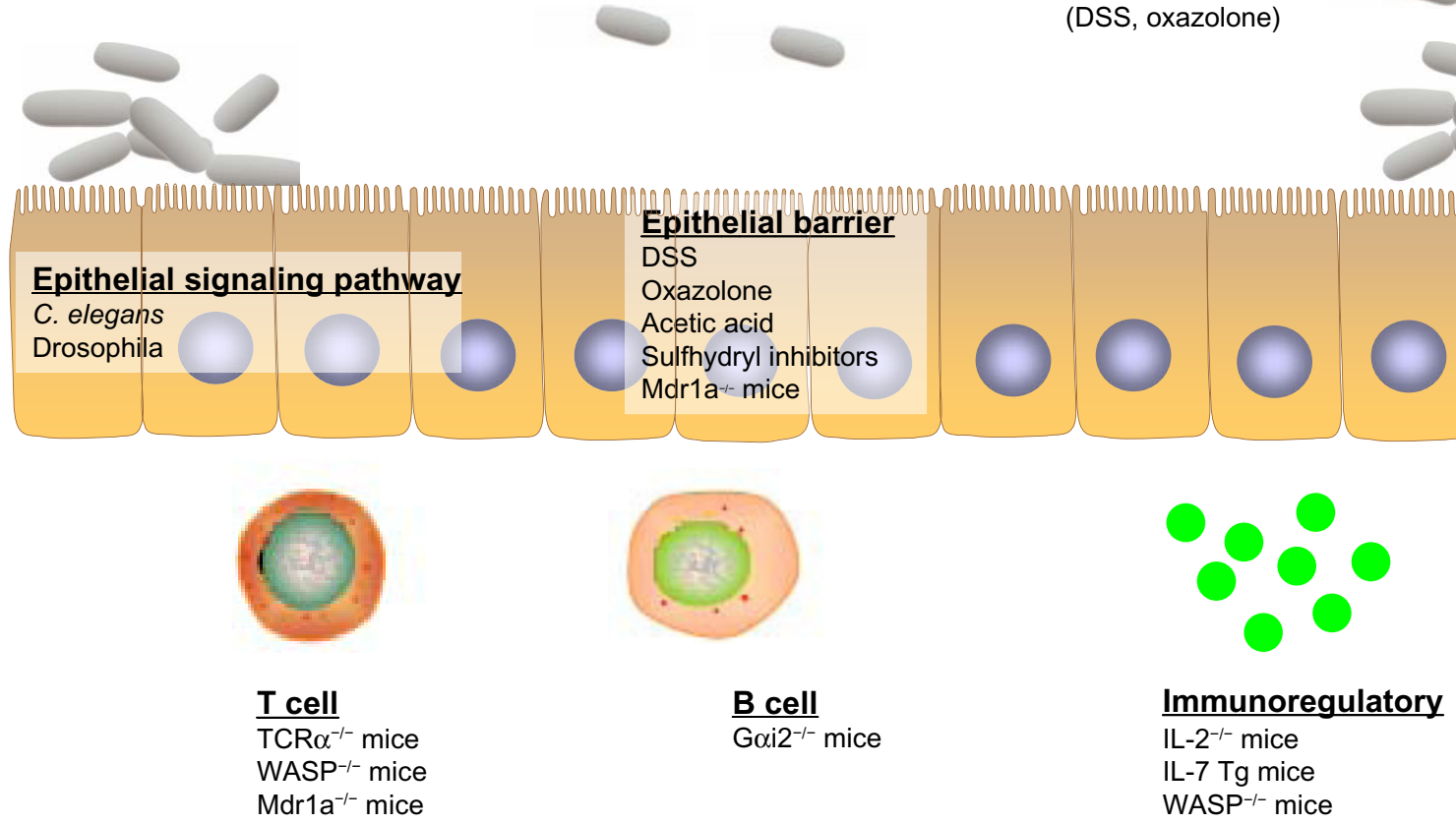

Figure 3 Ulcerative colitis (UC) models that address the specific framework of disease pathology. Invertebrate (eg, Caenorhabditis elegans, drosophila) and vertebrate (eg, zebrafish, mouse) models have their respective advantages in the study of UC pathogenesis. Different models can be utilized and carefully chosen to more appropriately address particular questions, mainly altered enteric microbial membership, intestinal epithelial dysregulation, and aberrant immune responses.

Abbreviations: AIEC, adherent-invasive Escherichia coli; DSS, dextran sulfate sodium; Goi2, guanine nucleotide-binding protein G(i) subunit $\alpha$-2; IL, interleukin; Mdr I a, multiple drug resistance Ia; TCR, T-cell receptor; Tg, transgenic; WASP, Wiskott-Aldrich syndrome protein.

organisms, further precise investigation can be performed using mouse models. It is important to first identify the most appropriate model that best represents the component in which the drug is exerting its effect: T-cell-mediated

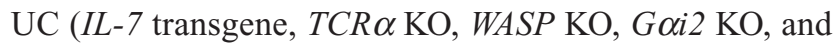
IL-2 KO mice), B-cell biology (Goi2 KO mice), intestinal barrier dysfunction (Mdrla KO mice), and signaling pathway dysregulation (Goi2 KO mice). Of note, the condition of animal husbandry and the cleanliness of the mouse facility (eg, GF, SPF, or CV) will have robust effects on the results, including the penetrance and severity of colitis in the mice.

If the drug candidate does not pertain to any specific pathway/process, chemically induced colitis mice may be a good approach. The advantage of using these methods, as compared with spontaneous models, is the ease of controlling the chemical dosage, which affects the extent and severity of colitis. This is particularly useful when multiple doses of the drug are to be administered. In addition, the duration of the induction is also highly controllable, hence allowing one to dissect between onset, acute, and recovery phases of the colitis.
When the desired outcome of the new candidate drug/ therapy is observed in the rodent colitis models, further investigation can be extended to larger animal models, such as porcine or sheep. ${ }^{72}$ The morphology and physiology of pig intestine share a high degree of similarity to those of humans and thus may better reflect responses in patients. Finally, positive findings of a novel therapeutic agent in preclinical testing in animal models can then be extended into a Phase I clinical trial for human UC patients.

\section{Role of animal models in the development of alternative and emerging ulcerative colitis treatments}

Current drug treatment for UC patients includes 5 aminosalicylic acid (5-ASA), corticosteroids, thiopurines, and anti-TNF $\alpha$ Abs. Except for 5-ASA, the mechanisms of action of which is not entirely clear, these therapies aim to exert immunosuppression to control the extent of inflammation. However, long-term efficacy is achieved only in approximately one-third of the patients with moderate to severe 
disease and is accompanied and restricted by adverse effects, including risks of infections, lymphoma, and nonmelanoma skin cancer. Animal models have provided a platform for insights into emerging therapies that hopefully will be more efficacious and/or safe (Figure 4).

\section{Antibodies targeting immune cell trafficking to the gut}

A potential target to treat chronic intestinal inflammation is to intervene with the process of immune cell recruitment and infiltration into the intestine. Leukocytes rapidly circulate through the microvasculature unless there is a specific signal for cells to exit the circulation and penetrate target organs. This process requires signaling between integrins on the endothelial surface (called adhesion molecules) and their receptors on the leukocyte surface membrane. Pertinent to the gut, mucosal addressin cell adhesion molecule-1 (MAdCAM-1) is expressed only in the intestinal tract and its associated lymphoid tissue and is recognized by its receptor $\alpha 4 \beta 7$ on the leukocyte surface, whereas vascular cell adhesion molecule- 1 is expressed on endothelial cells in other organs besides the intestinal mucosa and functions as a ligand for both receptors $\alpha 4 \beta 7$ and $\alpha 4 \beta 1 .{ }^{73}$ Studies in animal models from more than a decade ago demonstrated the efficacy of inhibiting these signals in the treatment of chronic colitis. Podolsky et $\mathrm{al}^{74}$ and Hesterberg et $\mathrm{al}^{75}$ demonstrated attenuation of acute colitis in cotton-top tamarins by administration of anti- $\alpha 4$ monoclonal antibody and anti$\alpha 4 \beta 7$ monoclonal antibody, respectively. At the same time, Picarella et $\mathrm{al}^{76}$ demonstrated the efficacy of $\mathrm{Abs}$ to $\beta 7$ and to MAdCAM-1 in ameliorating colitis induced by transfer of $\mathrm{CD}^{+} \mathrm{CD} 45 \mathrm{RB}^{\text {hi }}$ cells into lymphopenic mice. These preclinical studies demonstrated the proof of concept that interfering with leukocyte trafficking to the intestine could be effective colitis treatment.

Given that expression of mucosal adhesion molecules MAdCAM-1, intercellular adhesion molecule-1, and vascular cell adhesion molecule-1 have been described in mucosal tissues from patients with either $\mathrm{CD}$ or $\mathrm{UC}, \mathrm{Abs}$ to these molecules and their corresponding receptors were deemed favorable targets as novel therapies for IBD (Figure 5). ${ }^{77}$ Natalizumab, a monoclonal antibody to $\alpha 4$ integrin, was

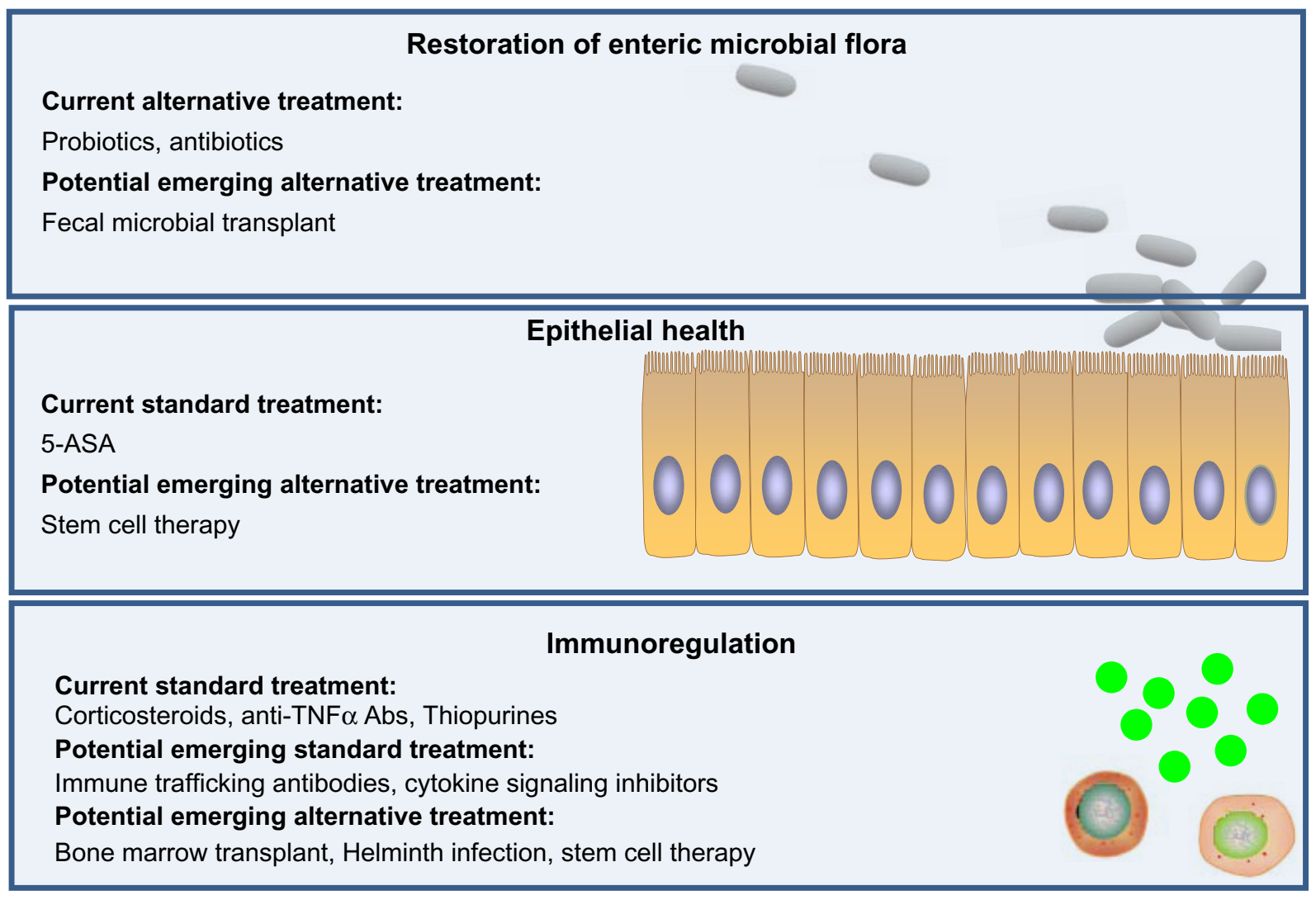

Figure 4 Current and emerging drug/therapy for ulcerative colitis (UC) treatment. Current treatments of UC mainly function by immunosuppression. Emerging therapies of UC have potential to target three major layers of UC dysfunction, including restoration of normal intestinal microbial flora, promotion of epithelial health (restitution of epithelium), and suppression of immunological cell trafficking and activation, with potentially fewer side effects compared with current available treatments. Abbreviations: 5-ASA, 5-aminosalicylic acid; Abs, antibodies; TNF, tumor necrosis factor. 


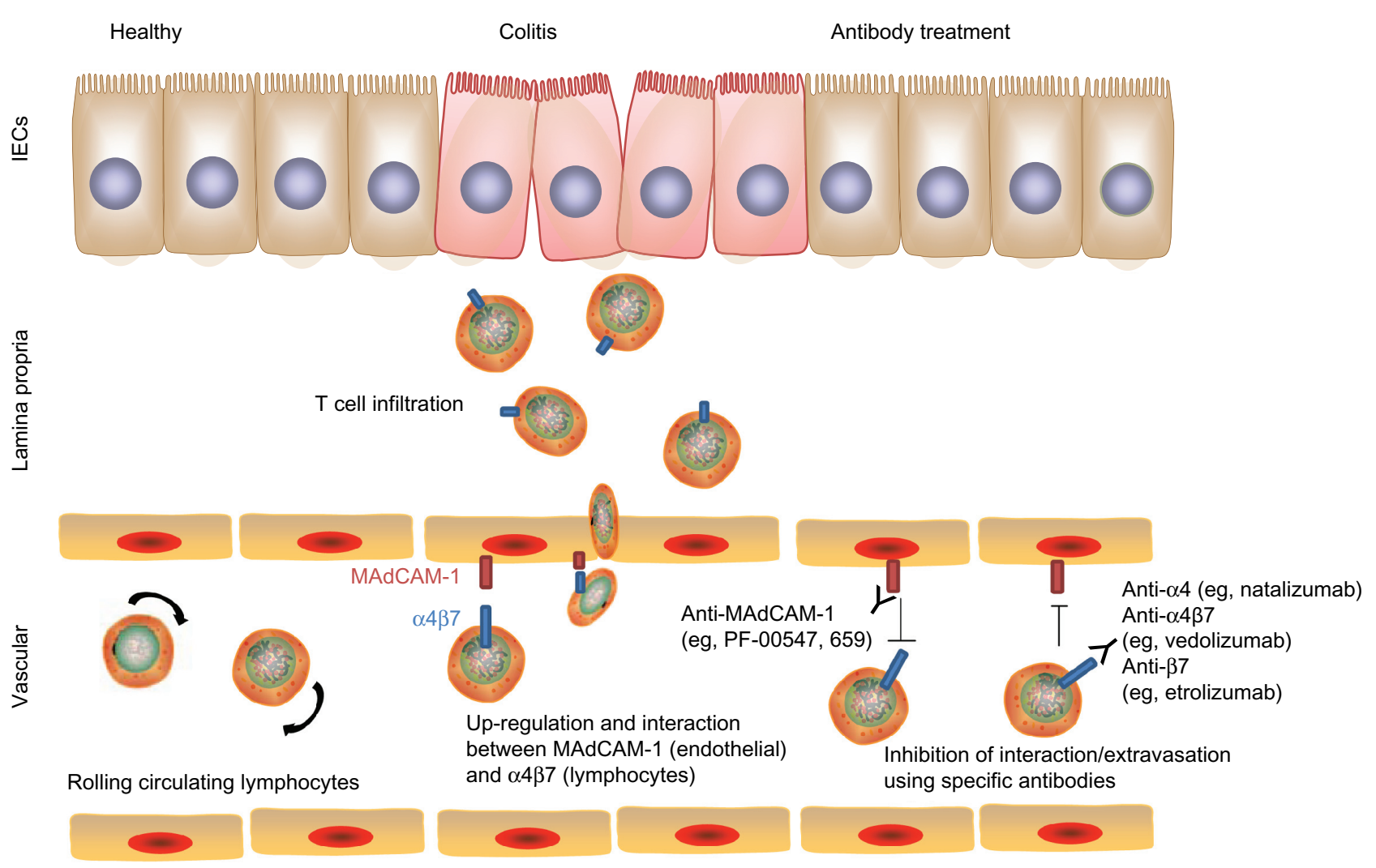

Figure 5 Blocking of immune cell trafficking to the colon. Upregulation of mucosal addressin cell adhesion molecule-I (MAdCAM-I) on intestinal vascular cells and expression of integrins (eg, $\alpha 4 \beta 7$ ) on lymphocytes promote interaction and adhesion of lymphocytes onto the intestinal endothelium and subsequent extravasation into colonic tissues. Blocking MAdCAM-I or $\alpha 4 \beta 7$ using specific antibodies disrupts this interaction and control of colitis severity.

Abbreviation: IECs, intestinal epithelial cells.

approved in 2008 by the US Food and Drug Administration (FDA) for severe, refractory CD after efficacy was documented. ${ }^{78,79}$ However, its use is highly limited due to the risk of progressive multifocal leukoencephalopathy, a potentially fatal demyelinating disease, given its interference with leukocyte homing to the central nervous system through blockade of $\alpha 4 \beta 1$ signaling. Therefore, targeting $\alpha 4 \beta 7$ more specifically with vedolizumab (aka MLN02 and MLN0002) should theoretically avoid this risk. Data from Phase III clinical trials demonstrate benefit in inducing and maintaining response in patients with moderately to severely active $\mathrm{CD}$ or $\mathrm{UC}$, with no case of progressive multifocal leukoencephalopathy reported thus far, despite more than 2,000 patients having received at least one dose of vedolizumab in a clinical trial setting. ${ }^{80}$ At this moment, vedolizumab is awaiting FDA approval for both CD and UC.

Similar to the idea of blocking $\alpha 4 \beta 7$, an antibody against $\beta 7$ and other specific inhibitors of trafficking to the gut are also actively being investigated, given encouraging results from animal studies. Based on the effect of $\beta 7$ antibody on the murine colitis model of $\mathrm{CD} 45 \mathrm{RB}^{\mathrm{hi}}$ transfer and the positive results from a Phase I study showing safety and a hint of efficacy, etrolizumab (aka rhuMAB $\beta 7$ ) is undergoing Phase II testing for UC. ${ }^{76,81}$ Similarly, MAdCAM-1 monoclonal antibody PF-00547,659 demonstrated some efficacy for UC. ${ }^{82}$ Even though alicaforsen (ISIS 2302), an inhibitor of intercellular adhesion molecule-1 (ICAM-1), was not obviously efficacious in $\mathrm{CD}$, an enema formulation of an ICAM-1 inhibitor was found to be comparable with mesalamine (a commonly used medication) in efficacy for left-sided UC. ${ }^{83-85}$ Overall, these results establish inhibitors of gut-homing molecules to be effective in treating IBD, as was seen in animal models in the 1990s.

\section{Inhibition of cytokine signaling}

Instead of inhibiting particular cytokines, one successful method of treatment has been through blocking the signaling pathway shared by multiple cytokines. Receptors within the IL-2R family (IL-2, IL-7, IL-9, IL-15, and IL-21) comprise two subunits, a shared common gamma subunit, and a second subunit that is specific to the particular cytokine. ${ }^{86}$ The common gamma subunit signals through activation of 
the protein tyrosine kinase Janus kinase 3 (Jak3), which is expressed solely in immune cells. Jak molecules then transduce the cytokine signal through different isoforms of signal transducer and activator of transcription (STAT), leading to downstream gene activation. As STAT3 activation is important in IL-6-mediated T-cell proliferation and in T-cellmediated colitis, given STAT3 $\mathrm{KO} C D 4{ }^{+} \mathrm{CD} 45 \mathrm{RB}^{\text {hi }}$ cells are unable to induce colitis when transferred into a lymphopenic host, and given STAT3 variants have been associated with increased risks of UC, a selective inhibitor of Jak3 represents a promising novel therapeutic option for colitis without other unwanted effects. ${ }^{6,87}$ Preclinical data are limited to one study demonstrating efficacy of intraperitoneal injection of Janex1, an inhibitor of Jak3, in attenuating TNBS-induced colitis, but given known benefits in transplant rejection, rheumatoid arthritis, and psoriasis, it was tried on UC. ${ }^{88}$ Phase II data revealed efficacy of tofacitinib, an oral Jak3 inhibitor, in inducing response and remission in moderately to severely active UC in a dose-dependent manner. ${ }^{89}$ Phase III clinical trials are undergoing, with hopes of FDA approval in the near future. If confirmed to be effective, tofacitinib would become the only nonsteroidal oral treatment to induce remission for moderately to severely active UC.

\section{Appendectomy}

Appendectomy, especially during childhood, is inversely associated with the risk of UC development and has been increasingly supported by both clinical and experimental studies. One of the earliest observations was reported in 1987 by Gilat et $\mathrm{al}^{90}$ in a study in search of childhood causal factors of IBD. Subsequently, a large Swedish cohort analyzing 212,963 patients (with matched controls) who had undergone appendectomy before the age of 50 years was followed for development of UC. ${ }^{91}$ It was found that inflammatory-associated appendectomy (eg, appendicitis or lymphadenitis), but not nonspecific abdominal pain, correlated with the lower risk of subsequent UC. Therefore, inflammation of the appendix preceding appendectomy, rather than appendectomy itself per se, appears to confer the protection against UC. Importantly, this correlation is specific to patients who have undergone appendectomy before the age of 20 years.

One of the earliest reports on the effect of appendectomy on experimental colitis in animal models was reported by Mizoguchi et $\mathrm{al}^{92}$ using the TCR $\alpha \mathrm{KO}$ mice. When appendectomy was performed in young (3-5 weeks) TCR $\alpha \mathrm{KO}$ mice, only $3.3 \%$ developed spontaneous intestinal inflammation after 6-7 months, with reduced MLN cell population, whereas up to $80 \%$ of sham-operated $T C R \alpha \mathrm{KO}$ mice developed colitis during the same period. The structure of the appendix lymphoid follicle is highly similar to intestinal $\mathrm{PP}$, and cellular proliferation rate in the appendix lymphoid follicle is twice that in the PP. ${ }^{92}$ Thus, it appears that appendixassociated/derived lymphocytes may hold key roles in UC development.

In a separate report, 7-day treatment with $2.5 \%$ DSS of mice that underwent appendectomy showed delayed onset and course of colitis development as compared with shamoperated mice. ${ }^{93}$ This was also accompanied with lower colonic damage scores and a reduction in ulcerated mucosal surface area. Interestingly, splenectomy did not show any benefits in DSS-induced colitis. Thus, although spleen enlargement is a frequent phenotype during DSS treatment, the fact that splenectomy did not confer protection suggests that this enlargement is a consequence, not a cause, of DSSinduced colitis.

Finally, the protective effect of appendectomy was also nicely demonstrated in a T-cell transfer colitis experiment. ${ }^{94}$ Fluorescence-labeled colitis-inducing $\mathrm{CD}^{2} 2 \mathrm{~L}^{+} \mathrm{CD}^{+}$cells that were transferred into immunodeficient severe combined immunodeficiency (SCID) mice were found to have a 3.5 -fold preferential homing toward the appendix than the colon and to express high levels of $\alpha 4 \beta 7$ adhesion molecule costimulatory molecule CD154. Therefore, with the help of various UC animal models, detailed characterization of the components within the appendix may further shed light on the pathophysiology underlying UC development to facilitate future therapeutic intervention attempts.

\section{Helminth therapy}

Increasing reports on both colitis mouse models as well as human UC clinical trials demonstrate that helminth infection provides beneficial effects on UC. Studies on helminth infection in UC mouse models have provided mechanistic insights into how the nematode induces tolerogenic DCs that can block colitis development and regulate T-cell responses. ${ }^{95}$ In addition to an immunoregulatory effect on adaptive immunity, evidence has supported that helminth infection can promote IL-22-mediated mucosal barrier regulation and gut microbiota to improve intestinal inflammation. ${ }^{96}$

The identification of these specific helminth factors can provide alternatively effective and safe treatment. It was demonstrated that injection of the hookworm Ancylostoma caninum-derived excretory/secretory factors can induce IL-4 ${ }^{+}$IL- $10^{+}$CD4 ${ }^{+}$T-cell response and ameliorate DSSinduced colitis in mice. ${ }^{97}$ To specifically determine the precise 
factors that have such protective effect, Cantacessi et al ${ }^{19}$ have characterized the transcriptome of Trichuris suis using next-generation sequencing. Recently, Du et a ${ }^{99}$ reported that subcutaneous injection into colitic mice with a recombinant of a helminth excretory-secretory protein called Trichinella spiralis $53 \mathrm{kDa}$ protein reduces disease activity index and macroscopic and microscopic inflammation score. Testing in UC animal models will hopefully further identify therapeutically effective products among helminth-derived factors to broaden clinical treatment options.

Amidst the success of helminth therapy in mouse models and human clinical trials, several reports have provided different effects and perspectives. Recently, Bager et a $\mathrm{l}^{100} \mathrm{dem}$ onstrated in population-based cohort studies that infection of the helminth pinworm that causes enterobiasis does not lower the risk of UC. They suggested that, in contrast to pinworms, hookworms or schistosomes thrive in tropical countries, and thus the higher rates of chronic inflammatory disease, including $\mathrm{UC}$, in nontropical regions may be an effect of the absence of tropical helminth. In addition, Wang et a ${ }^{101}$ have also reported an exacerbation of disease by the tapeworm Hymenolepis diminuta infected into oxazolone-induced colitic mice through IL-5-mediated immune responses. These data suggest that perhaps not all helminth are protective, and careful characterization of helminth-based therapy in mouse models is critical to identify the efficacy and safety aspects before proceeding to human clinical trials. ${ }^{102}$

\section{Stem cell-based therapy}

Pluripotent cell-based therapy for CD is in Phase I trials, which may provide informative insights in the treatments for UC patients as well. ${ }^{103}$ Colitic $I L-10 \mathrm{KO}$ mice that were injected with nondifferentiated embryonic stem cells tagged with yellow fluorescence protein showed homing in the colon, small intestine, liver, and thymus tissues, but not in the spleen or bone marrow, associated with improved colitis inflammatory scores upon transplantation. ${ }^{104}$ In addition, transplantation of IECs from in vivo predifferentiated embryonic stem cells into mice was also found effective in reducing inflammation and in restoration of immune balance. A similar test using $I L-10 \mathrm{KO}$ mice with active colitis was performed through intracolonic infusion of colonic stem cells, which showed an ameliorative effect on colitis. ${ }^{105}$ The authors therefore suggested that colonic stem cells provide a safer option for colitis treatment, as compared with those of systemic stem cell administration.

Bone-marrow derived cells (BMDCs) have also been demonstrated to control the extent of inflammation when transplanted into colitic mice. Lethally irradiated DSSinduced colitic mice transplanted with BMDCs from green fluorescence protein (GFP) Tg mice showed the presence of GFP in vimentin ${ }^{+}$colonic interstitial cells, but not $\mathrm{Ki}-67^{+}-$ proliferating cells, cytokeratin ${ }^{+}$epithelial cells, or CD $31^{+}$ endothelial cells. ${ }^{106}$ The transplanted GFP BMDCs frequently transdifferentiated into subepithelial myofibroblasts and fibroblasts that reside in the colonic subepithelium even after recovery. To fully correct the immunodysregulation in colitis, it was demonstrated that total body irradiation followed by transplantation of BMDCs is more effective in ameliorating colitis in mice. ${ }^{107}$

Systemic infusion of mesenchymal stem cells (MSCs) in DSS-induced colitis mice also ameliorated colitis, characterized by downregulation of TNF $\alpha$ and IL-1 $\beta .{ }^{108}$ Mechanistically, MSC systemic infusion induced transient T-cell apoptosis via the Fas/Fas ligand-dependent apoptotic pathway. ${ }^{109}$ The apoptotic $\mathrm{T}$ cells then trigger macrophages to produce high levels of transforming growth factor- $\beta$, resulting in the upregulation of $\mathrm{CD} 4^{+} \mathrm{CD} 25^{+} \mathrm{Foxp} 3^{+}$Treg production and, eventually, enhanced immune tolerance. Colitic rats showed the presence of the transplanted MSCs only in the LP. ${ }^{110}$ In addition, topical implantation, rather than systemic transplantation, of MSCs into the chemically injured intestinal area is sufficient to promote the healing process. ${ }^{111}$ This success utilizing stem cell therapy in animal models is promising as an emerging therapy for human disease and has been studied in clinical trials. ${ }^{103}$ Further investigation in animal models will aid in determining the long-term fate of the engrafted stem cells, to ensure long-term safety of this mode of UC therapy.

\section{Fecal microbiota transplant}

Aiming to balance the dysregulated intestinal microbiome has been attempted through probiotics treatment, with some degree of success in clinical and animal studies. ${ }^{12}$ However, the outcome is nevertheless variable and modest, and so probiotics are considered supplementary and not substitutes for conventional therapy. Therefore, the potential of fecal microbiota transplantation (FMT) to regulate the homeostasis of the abnormal intestinal microbiota now poses an attractive alternative method for UC treatment.

One of the pioneering investigations of FMT as a UC treatment was reported by Bennet and Brinkman, ${ }^{113}$ where Bennet himself was suffering from UC and self-experimented with FMT, reporting improvements after 3 months with resolution of symptoms after 6 months. Although it is perceived that the normal flora present in FMT donors can 
restore the normal balance in dysregulated microbial flora in IBD patients, the proper mechanism behind the FMT effect is currently still obscure. Mice that were deficient in nucleotide-binding oligomerization domain 2 and given FMT showed a reduced disease risk and long-term changes in microbiota compositions. ${ }^{114}$ Conversely, wild-type mice that were transplanted with the dysregulated fecal microbiota derived from nucleotide-binding oligomerization domain $2 \mathrm{KO}$ mice showed increased disease risk, suggesting the presence of particular microbial subsets that may be protective or colitogenic.

Recent survey results have revealed that the majority of UC patients show keen interest in considering FMT in their treatment regimen. ${ }^{115}$ With the emerging technology and maturation of humanized mouse models, mouse models of UC will serve as a valuable tool to elucidate the mechanism behind FMT beneficial effects, as well as to define proper safety issues and long-term effects.

\section{Herbal and plant extracts}

The therapeutic effects of herbal or plant extracts have been exploited for centuries, and identifying and characterizing these components can provide alternative treatment options for UC patients. These include both Western-derived herbs as well as traditional Chinese medicine. Many of the reported randomized clinical trials compared the efficacy of these alternative agents with that of standard treatments (ie, 5-ASA, sulfasalazine, and steroids) or placebo. A literature review reported that the number of subjects who have undergone clinical trials using a herbal treatment for UC from 1947 to 2013 ranges from 14 to 224 subjects, with treatment duration lasting for 4-12 weeks. ${ }^{116}$ No major adverse reactions, other than minor side effects, including nausea, constipation, and flatulence, were reported to be associated with these different herbal treatments. ${ }^{116}$ The major herb/plant extracts that have been shown to have potential benefit for UC include aloe vera, Boswellia serrata, butyrate, licorice, slippery elm, tormential extracts, wheat grass, curcumin, bromelain, and psyllium (see review by $\mathrm{Ke}$ et $\mathrm{al}^{117}$ ). One main aim of the treatment is to induce remission of UC, whereby aloe vera, wheat grass, and HMPL-004 (Andrographis paniculata extract) appear to have some efficacy when compared with placebo controls. ${ }^{118-120}$ Another major goal of herb/plant extract therapy is to maintain remission in UC, in which curcumin, myrrh, chamomile extracts, and coffee charcoal treatment in patients results in a relapsed rate that is comparable with 5-ASA-treated patients in randomized clinical trial reports. ${ }^{121,122}$ However, caution needs to be taken in interpreting these observations, given many of these studies were done on patients with only mild disease, treatment effects were not rigorously tested with objective endpoints in all studies, and long-term safety and efficacy are not known.

Given some hint of efficacy, it is important to understand the underlying mechanisms behind the potential therapeutic effects of these herbs and plant extracts by using UC animal models. For instance, A. paniculata extract (HMPL-004) has been demonstrated to reduce splenic $\mathrm{CD}^{+} \mathrm{T}$ cells as well as inhibit $\mathrm{CD}^{+}{ }^{+} \mathrm{T}$-cell proliferation and differentiation into Th1/Th17 effector cells in a murine CD45RB ${ }^{\text {hi }}$ cell transfer model. ${ }^{123}$ In Mdrla $\mathrm{KO}$ colitic mice, reduction of colitis histological signs by curcumin treatment is associated with upregulation of xenobiotic metabolism and also downregulation of proinflammatory pathways. ${ }^{55}$ These studies provide further in vivo mechanistic understanding of how each individual herb/plant extract may work, facilitating the choice of the most appropriate herbal treatment for defined groups of patients.

\section{Conclusion}

Animal models have become indispensable tools to study mechanisms and treatments of diseases. Insights learned from such models allow us to design novel therapeutic strategies and to define, in a preclinical setting, the safety and efficacy of such novel treatments before human clinical trials. The fact that there are currently numerous models available also indicates that no single model is perfect, and it is therefore essential to define the specific question in mind, in order to identify the ideal model for study.

\section{Disclosure}

This work has been supported by the National Institutes of Health (NIH) (DK80070) and grants from the Eli and Edythe L Broad Medical Foundation and American Gastroenterological Association Foundation to EM and NIH DK83430 to DDN. DL has been awarded the Singapore A*STAR International Fellowship.

\section{References}

1. Molodecky NA, Soon IS, Rabi DM, et al. Increasing incidence and prevalence of the inflammatory bowel diseases with time, based on systematic review. Gastroenterology. 2012;142(1):46-54 e42; quiz e30.

2. Loftus EV Jr, Sandborn WJ. Epidemiology of inflammatory bowel disease. Gastroenterol Clin North Am. 2002;31(1):1-20.

3. Park KT, Bass D. Inflammatory bowel disease-attributable costs and cost-effective strategies in the United States: a review. Inflamm Bowel Dis. 2011;17(7):1603-1609.

4. Akolkar PN, Gulwani-Akolkar B, Heresbach D, et al. Differences in risk of Crohn's disease in offspring of mothers and fathers with inflammatory bowel disease. Am J Gastroenterol. 1997;92(12):2241-2244. 
5. Fransen K, Mitrovic M, van Diemen CC, et al. Limited evidence for parent-of-origin effects in inflammatory bowel disease associated loci. PLoS One. 2012;7(9):e45287.

6. Anderson CA, Boucher G, Lees CW, et al. Meta-analysis identifies 29 additional ulcerative colitis risk loci, increasing the number of confirmed associations to 47. Nat Genet. 2011;43(3):246-252.

7. Lewis JD, Aberra FN, Lichtenstein GR, Bilker WB, Brensinger C, Strom BL. Seasonal variation in flares of inflammatory bowel disease. Gastroenterology. 2004;126(3):665-673.

8. Mahid SS, Minor KS, Soto RE, Hornung CA, Galandiuk S. Smoking and inflammatory bowel disease: a meta-analysis. Mayo Clin Proc. 2006;81(11):1462-1471.

9. Bergeron V, Grondin V, Rajca S, et al. Current smoking differentially affects blood mononuclear cells from patients with Crohn's disease and ulcerative colitis: relevance to its adverse role in the disease. Inflamm Bowel Dis. 2012;18(6):1101-1111.

10. Denson LA, Long MD, McGovern DP, et al. Challenges in IBD research: update on progress and prioritization of the CCFA's research agenda. Inflamm Bowel Dis. 2013;19(4):677-682.

11. Kawada M, Arihiro A, Mizoguchi E. Insights from advances in research of chemically induced experimental models of human inflammatory bowel disease. World J Gastroenterol. 2007;13(42):5581-5593.

12. Mizoguchi A. Animal models of inflammatory bowel disease. In: Conn PM, ed. Progress in Molecular Biology and Translational Science. Vol 105. San Diego, CA: Academic Press; 2012.

13. Boirivant M, Fuss IJ, Chu A, Strober W. Oxazolone colitis: a murine model of $\mathrm{T}$ helper cell type 2 colitis treatable with antibodies to interleukin 4. J Exp Med. 1998;188(10):1929-1939.

14. Heller F, Fuss IJ, Nieuwenhuis EE, Blumberg RS, Strober W. Oxazolone colitis, a Th2 colitis model resembling ulcerative colitis, is mediated by IL-13-producing NK-T cells. Immunity. 2002;17(5):629-638.

15. Ikeda $M$, Takeshima $F$, Isomoto $H$, et al. Simvastatin attenuates trinitrobenzene sulfonic acid-induced colitis, but not oxazalone-induced colitis. Dig Dis Sci. 2008;53(7):1869-1875.

16. Galitovskiy V, Qian J, Chernyavsky AI, et al. Cytokine-induced alterations of alpha7 nicotinic receptor in colonic $\mathrm{CD} 4 \mathrm{~T}$ cells mediate dichotomous response to nicotine in murine models of Th1/Th17- versus Th2-mediated colitis. J Immunol. 2011;187(5):2677-2687.

17. MacPherson BR, Pfeiffer CJ. Experimental production of diffuse colitis in rats. Digestion. 1978;17(2):135-150.

18. Elson CO, Sartor RB, Tennyson GS, Riddell RH. Experimental models of inflammatory bowel disease. Gastroenterology. 1995;109(4): 1344-1367.

19. Cetinkaya A, Bulbuloglu E, Kurutas EB, Ciralik H, Kantarceken B, Buyukbese MA. Beneficial effects of N-acetylcysteine on acetic acidinduced colitis in rats. Tohoku J Exp Med. 2005;206(2):131-139.

20. Kuralay F, Yildiz C, Ozutemiz O, et al. Effects of trimetazidine on acetic acid-induced colitis in female Swiss rats. J Toxicol Environ Health A. 2003;66(2):169-179.

21. Yoshida N, Yoshikawa T, Yamaguchi T, et al. A novel water-soluble vitamin E derivative protects against experimental colitis in rats. Antioxid Redox Signal. 1999;1(4):555-562.

22. Tahan G, Gramignoli R, Marongiu F, et al. Melatonin expresses powerful anti-inflammatory and antioxidant activities resulting in complete improvement of acetic-acid-induced colitis in rats. Dig Dis Sci. 2011;56(3):715-720.

23. Mann BJ, Burkholder BV, Lockhart LA. Protection in a gerbil model of amebiasis by oral immunization with Salmonella expressing the galactose/ $\mathrm{N}$-acetyl D-galactosamine inhibitable lectin of Entamoeba histolytica. Vaccine. 1997;15(6-7):659-663.

24. Mizoguchi E. Chitinase 3-like-1 exacerbates intestinal inflammation by enhancing bacterial adhesion and invasion in colonic epithelial cells. Gastroenterology. 2006;130(2):398-411.

25. Boudeau J, Glasser AL, Masseret E, Joly B, Darfeuille-Michaud A. Invasive ability of an Escherichia coli strain isolated from the ileal mucosa of a patient with Crohn's disease. Infect Immun. 1999;67(9): 4499-4509.
26. Jensen SR, Fink LN, Nielsen OH, Brynskov J, Brix S. Ex vivo intestinal adhesion of Escherichia coli LF82 in Crohn's disease. Microb Pathog. 2011;51(6):426-431.

27. Low D, Tran HT, Lee IA, et al. Chitin-binding domains of Escherichia coli chiA mediate interactions with intestinal epithelial cells in mice with colitis. Gastroenterology. 2013;145(3):602-612.

28. Nagatani K, Wang S, Llado V, et al. Chitin microparticles for the control of intestinal inflammation. Inflamm Bowel Dis. 2012;18(9): $1698-1710$.

29. Ingrassia I, Leplingard A, Darfeuille-Michaud A. Lactobacillus casei DN-114 001 inhibits the ability of adherent-invasive Escherichia coli isolated from Crohn's disease patients to adhere to and to invade intestinal epithelial cells. Appl Environ Microbiol. 2005;71(6): 2880-2887.

30. Drouet M, Vignal C, Singer E, et al. AIEC colonization and pathogenicity: influence of previous antibiotic treatment and preexisting inflammation. Inflamm Bowel Dis. 2012;18(10):1923-1931.

31. Watanabe M, Ueno Y, Yajima T, et al. Interleukin 7 is produced by human intestinal epithelial cells and regulates the proliferation of intestinal mucosal lymphocytes. J Clin Invest. 1995;95(6):2945-2953.

32. Watanabe $\mathrm{M}$, Watanabe $\mathrm{N}$, Iwao $\mathrm{Y}$, et al. The serum factor from patients with ulcerative colitis that induces $\mathrm{T}$ cell proliferation in the mouse thymus is interleukin-7. J Clin Immunol. 1997;17(4):282-292.

33. Shinohara T, Nemoto Y, Kanai T, et al. Upregulated IL-7 receptor alpha expression on colitogenic memory CD4+ $\mathrm{T}$ cells may participate in the development and persistence of chronic colitis. J Immunol. 2011;186(4):2623-2632.

34. Yamazaki M, Yajima T, Tanabe M, et al. Mucosal T cells expressing high levels of IL-7 receptor are potential targets for treatment of chronic colitis. J Immunol. 2003;171(3):1556-1563.

35. Willis CR, Seamons A, Maxwell J, et al. Interleukin-7 receptor blockade suppresses adaptive and innate inflammatory responses in experimental colitis. J Inflamm (Lond). 2012;9(1):39.

36. Watanabe M, Ueno Y, Yajima T, et al. Interleukin 7 transgenic mice develop chronic colitis with decreased interleukin 7 protein accumulation in the colonic mucosa. $J$ Exp Med. 1998;187(3):389-402.

37. Mombaerts P, Mizoguchi E, Grusby MJ, Glimcher LH, Bhan AK, Tonegawa S. Spontaneous development of inflammatory bowel disease in T cell receptor mutant mice. Cell. 1993;75(2):274-282.

38. Dianda L, Hanby AM, Wright NA, Sebesteny A, Hayday AC, Owen MJ. $\mathrm{T}$ cell receptor-alpha beta-deficient mice fail to develop colitis in the absence of a microbial environment. Am J Pathol. 1997;150(1): 91-97.

39. Shimomura Y, Mizoguchi E, Sugimoto K, et al. Regulatory role of B-1 B cells in chronic colitis. Int Immunol. 2008;20(6):729-737.

40. Nishiyori A, Nagakura Y, Ichikawa K. Piroxicam accelerates development of colitis in T-cell receptor alpha chain-deficient mice. Eur $J$ Pharmacol. 2009;615(1-3):241-245.

41. Iijima H, Takahashi I, Kishi D, et al. Alteration of interleukin 4 production results in the inhibition of $\mathrm{T}$ helper type 2 cell-dominated inflammatory bowel disease in $\mathrm{T}$ cell receptor alpha chain-deficient mice. J Exp Med. 1999;190(5):607-615.

42. Mizoguchi A, Mizoguchi E, Smith RN, Preffer FI, Bhan AK. Suppressive role of B cells in chronic colitis of T cell receptor alpha mutant mice. J Exp Med. 1997;186(10):1749-1756.

43. Sheikh SZ, Hegazi RA, Kobayashi T, et al. An anti-inflammatory role for carbon monoxide and heme oxygenase- 1 in chronic Th2-mediated murine colitis. J Immunol. 2011;186(9):5506-5513.

44. Hsieh KH, Chang MH, Lee CY, Wang CY. Wiskott-Aldrich syndrome and inflammatory bowel disease. Ann Allergy. 1988;60(5):429-431.

45. Dupuis-Girod S, Medioni J, Haddad E, et al. Autoimmunity in WiskottAldrich syndrome: risk factors, clinical features, and outcome in a single-center cohort of 55 patients. Pediatrics. 2003;111(5 Pt 1): e622-e627.

46. Snapper SB, Rosen FS, Mizoguchi E, et al. Wiskott-Aldrich syndrome protein-deficient mice reveal a role for WASP in T but not B cell activation. Immunity. 1998;9(1):81-91. 
47. Nguyen DD, Maillard MH, Cotta-de-Almeida V, et al. Lymphocytedependent and Th2 cytokine-associated colitis in mice deficient in Wiskott-Aldrich syndrome protein. Gastroenterology. 2007;133(4): 1188-1197.

48. Nguyen DD, Wurbel MA, Goettel JA, et al. Wiskott-Aldrich syndrome protein deficiency in innate immune cells leads to mucosal immune dysregulation and colitis in mice. Gastroenterology. 2012;143(3): 719-729.

49. Klein C, Nguyen D, Liu CH, et al. Gene therapy for Wiskott-Aldrich syndrome: rescue of T-cell signaling and amelioration of colitis upon transplantation of retrovirally transduced hematopoietic stem cells in mice. Blood. 2003;101(6):2159-2166.

50. Tuin A, Poelstra K, de Jager-Krikken A, et al. Role of alkaline phosphatase in colitis in man and rats. Gut. 2009;58(3):379-387.

51. Ramasamy S, Nguyen DD, Eston MA, et al. Intestinal alkaline phosphatase has beneficial effects in mouse models of chronic colitis. Inflamm Bowel Dis. 2011;17(2):532-542.

52. Panwala CM, Jones JC, Viney JL. A novel model of inflammatory bowel disease: mice deficient for the multiple drug resistance gene, mdr1a spontaneously develop colitis. J Immunol. 1998;161(10):5733-5744.

53. Tanner SM, Staley EM, Lorenz RG. Altered generation of induced regulatory T cells in the FVB.mdr1a-/- mouse model of colitis. Mucosal Immunol. 2013;6(2):309-323.

54. Staley EM, Dimmitt RA, Schoeb TR, Tanner SM, Lorenz RG. Critical role for P-glycoprotein expression in hematopoietic cells in the FVB. Mdr1a(-/-) model of colitis. J Pediatr Gastroenterol Nutr. 2011;53(6): 666-673.

55. Nones K, Dommels YE, Martell S, et al. The effects of dietary curcumin and rutin on colonic inflammation and gene expression in multidrug resistance gene-deficient (mdr1a-/-) mice, a model of inflammatory bowel diseases. Br J Nutr. 2009;101(2):169-181.

56. Annese V, Valvano MR, Palmieri O, Latiano A, Bossa F, Andriulli A. Multidrug resistance 1 gene in inflammatory bowel disease: a metaanalysis. World J Gastroenterol. 2006;12(23):3636-3644.

57. Langmann T, Moehle C, Mauerer R, et al. Loss of detoxification in inflammatory bowel disease: dysregulation of pregnane $\mathrm{X}$ receptor target genes. Gastroenterology. 2004;127(1):26-40.

58. Saksena S, Goyal S, Raheja G, et al. Upregulation of P-glycoprotein by probiotics in intestinal epithelial cells and in the dextran sulfate sodium model of colitis in mice. Am J Physiol Gastrointest Liver Physiol. 2011;300(6):G1115-G1123.

59. Sadlack B, Merz H, Schorle H, Schimpl A, Feller AC, Horak I. Ulcerative colitis-like disease in mice with a disrupted interleukin-2 gene. Cell. 1993;75(2):253-261

60. Cruickshank SM, English NR, Felsburg PJ, Carding SR. Characterization of colonic dendritic cells in normal and colitic mice. World $J$ Gastroenterol. 2005;11(40):6338-6347.

61. Waidmann M, Bechtold O, Frick JS, et al. Bacteroides vulgatus protects against Escherichia coli-induced colitis in gnotobiotic interleukin-2deficient mice. Gastroenterology. 2003;125(1):162-177.

62. Muller M, Fink K, Geisel J, et al. Intestinal colonization of IL-2 deficient mice with non-colitogenic B. vulgatus prevents DC maturation and T-cell polarization. PLoS One. 2008;3(6):e2376.

63. Contractor NV, Bassiri H, Reya T, et al. Lymphoid hyperplasia, autoimmunity, and compromised intestinal intraepithelial lymphocyte development in colitis-free gnotobiotic IL-2-deficient mice. J Immunol. 1998;160(1):385-394.

64. Ludviksson BR, Strober W, Nishikomori R, Hasan SK, Ehrhardt RO Administration of $\mathrm{mAb}$ against alpha $\mathrm{E}$ beta 7 prevents and ameliorates immunization-induced colitis in IL-2-/- mice. J Immunol. 1999;162(8): 4975-4982.

65. Varilek GW, Yang F, Lee EY, et al. Green tea polyphenol extract attenuates inflammation in interleukin-2-deficient mice, a model of autoimmunity. J Nutr. 2001;131(7):2034-2039.

66. Rudolph U, Finegold MJ, Rich SS, et al. Ulcerative colitis and adenocarcinoma of the colon in G alpha i2-deficient mice. Nat Genet. 1995;10(2):143-150.
67. Hornquist CE, Lu X, Rogers-Fani PM, et al. G(alpha)i2-deficient mice with colitis exhibit a local increase in memory CD4+ T cells and proinflammatory Th1-type cytokines. J Immunol. 1997;158(3): 1068-1077.

68. Bjursten M, Willen R, Hultgren Hornquist E. Transfer of colitis by Galphai2-deficient T lymphocytes: impact of subpopulations and tissue origin. Inflamm Bowel Dis. 2005;11(11):997-1005.

69. Dalwadi H, Wei B, Schrage M, et al. B cell developmental requirement for the G alpha i2 gene. J Immunol. 2003;170(4):1707-1715.

70. Ohman L, Willen R, Hultgren $\mathrm{OH}$, Hultgren Hornquist E. Acellular Bordetella pertussis vaccine enhances mucosal interleukin-10 production, induces apoptosis of activated Th1 cells and attenuates colitis in Galphai2-deficient mice. Clin Exp Immunol. 2005;141(1):37-46.

71. Fritsch Fredin M, Vidal A, Utkovic H, et al. The application and relevance of ex vivo culture systems for assessment of IBD treatment in murine models of colitis. Pharmacol Res. 2008;58(3-4): 222-231.

72. Lin J, Hackam DJ. Worms, flies and four-legged friends: the applicability of biological models to the understanding of intestinal inflammatory diseases. Dis Model Mech. 2011;4(4):447-456.

73. Briskin M, Winsor-Hines D, Shyjan A, et al. Human mucosal addressin cell adhesion molecule-1 is preferentially expressed in intestinal tract and associated lymphoid tissue. Am J Pathol. 1997;151(1):97-110.

74. Podolsky DK, Lobb R, King N, et al. Attenuation of colitis in the cotton-top tamarin by anti-alpha 4 integrin monoclonal antibody. J Clin Invest. 1993;92(1):372-380.

75. Hesterberg PE, Winsor-Hines D, Briskin MJ, et al. Rapid resolution of chronic colitis in the cotton-top tamarin with an antibody to a gut-homing integrin alpha 4 beta 7. Gastroenterology. 1996;111(5): $1373-1380$

76. Picarella D, Hurlbut P, Rottman J, Shi X, Butcher E, Ringler DJ. Monoclonal antibodies specific for beta 7 integrin and mucosal addressin cell adhesion molecule-1 (MAdCAM-1) reduce inflammation in the colon of scid mice reconstituted with CD45RBhigh CD4+ T cells. J Immunol. 1997;158(5):2099-2106.

77. Neurath MF. New targets for mucosal healing and therapy in inflammatory bowel diseases. Mucosal Immunol. In press 2013.

78. Sandborn WJ, Colombel JF, Enns R, et al. Natalizumab induction and maintenance therapy for Crohn's disease. N Engl J Med. 2005;353(18): 1912-1925.

79. Targan SR, Feagan BG, Fedorak RN, et al. Natalizumab for the treatment of active Crohn's disease: results of the ENCORE trial. Gastroenterology. 2007;132(5):1672-1683.

80. Feagan BG, Rutgeerts P, Sands BE, et al. Vedolizumab as induction and maintenance therapy for ulcerative colitis. $N$ Engl J Med. 2013;369(8):699-710.

81. Rutgeerts PJ, Fedorak RN, Hommes DW, et al. A randomised phase I study of etrolizumab (rhuMAb beta7) in moderate to severe ulcerative colitis. Gut. 2013;62(8):1122-1130

82. Vermeire S, Ghosh S, Panes J, et al. The mucosal addressin cell adhesion molecule antibody PF-00547,659 in ulcerative colitis: a randomised study. Gut. 2011;60(8):1068-1075.

83. Yacyshyn BR, Bowen-Yacyshyn MB, Jewell L, et al. A placebocontrolled trial of ICAM-1 antisense oligonucleotide in the treatment of Crohn's disease. Gastroenterology. 1998;114(6):1133-1142.

84. Yacyshyn BR, Chey WY, Goff J, et al. Double blind, placebo controlled trial of the remission inducing and steroid sparing properties of an ICAM-1 antisense oligodeoxynucleotide, alicaforsen (ISIS 2302), in active steroid dependent Crohn's disease. Gut. 2002;51(1):30-36.

85. Miner PB Jr, Wedel MK, Xia S, Baker BF. Safety and efficacy of two dose formulations of alicaforsen enema compared with mesalazine enema for treatment of mild to moderate left-sided ulcerative colitis: a randomized, double-blind, active-controlled trial. Aliment Pharmacol Ther. 2006;23(10):1403-1413.

86. Coskun M, Salem M, Pedersen J, Nielsen OH. Involvement of JAK/ STAT signaling in the pathogenesis of inflammatory bowel disease. Pharmacol Res. 2013;76C:1-8. 
87. Durant L, Watford WT, Ramos HL, et al. Diverse targets of the transcription factor STAT3 contribute to $\mathrm{T}$ cell pathogenicity and homeostasis. Immunity. 2010;32(5):605-615.

88. Uckun FM, Tibbles H, Ozer Z, Qazi S, Vassilev A. Anti-inflammatory activity profile of JANEX-1 in preclinical animal models. Bioorg Med Chem. 2008;16(3):1287-1298.

89. Sandborn WJ, Ghosh S, Panes J, et al. Tofacitinib, an oral Janus kinase inhibitor, in active ulcerative colitis. $N$ Engl J Med. 2012;367(7): 616-624.

90. Gilat T, Hacohen D, Lilos P, Langman MJ. Childhood factors in ulcerative colitis and Crohn's disease. An international cooperative study. Scand J Gastroenterol. 1987;22(8):1009-1024.

91. Andersson RE, Olaison G, Tysk C, Ekbom A. Appendectomy and protection against ulcerative colitis. $N$ Engl J Med. 2001;344(11): 808-814.

92. Mizoguchi A, Mizoguchi E, Chiba C, Bhan AK. Role of appendix in the development of inflammatory bowel disease in TCR-alpha mutant mice. J Exp Med. 1996;184(2):707-715.

93. Krieglstein CF, Cerwinka WH, Laroux FS, et al. Role of appendix and spleen in experimental colitis. J Surg Res. 2001;101(2):166-175.

94. Farkas SA, Hornung M, Sattler C, et al. Preferential migration of CD62L cells into the appendix in mice with experimental chronic colitis. Eur Surg Res. 2005;37(2):115-122.

95. Blum AM, Hang L, Setiawan T, et al. Heligmosomoides polygyrus bakeri induces tolerogenic dendritic cells that block colitis and prevent antigen-specific gut T cell responses. J Immunol. 2012;189(5): 2512-2520.

96. Leung JM, Loke P. A role for IL-22 in the relationship between intestinal helminths, gut microbiota and mucosal immunity. Int J Parasitol. 2013;43(3-4):253-257.

97. Ferreira I, Smyth D, Gaze S, et al. Hookworm excretory/secretory products induce interleukin-4 (IL-4)+ IL-10+ CD4+ T cell responses and suppress pathology in a mouse model of colitis. Infect Immun. 2013;81(6):2104-2111.

98. Cantacessi C, Young ND, Nejsum P, et al. The transcriptome of Trichuris suis: first molecular insights into a parasite with curative properties for key immune diseases of humans. PLoS One. 2011;6(8):e23590.

99. Du L, Tang H, Ma Z, et al. The protective effect of the recombinant 53-kDa protein of Trichinella spiralis on experimental colitis in mice. Dig Dis Sci. 2011;56(10):2810-2817.

100. Bager P, Vinkel Hansen A, Wohlfahrt J, Melbye M. Helminth infection does not reduce risk for chronic inflammatory disease in a populationbased cohort study. Gastroenterology. 2012;142(1):55-62.

101. Wang A, Fernando M, Leung G, Phan V, Smyth D, McKay DM. Exacerbation of oxazolone colitis by infection with the helminth Hymenolepis diminuta: involvement of IL-5 and eosinophils. Am J Pathol. 2010;177(6):2850-2859.

102. Wang LJ, Cao Y, Shi HN. Helminth infections and intestinal inflammation. World J Gastroenterol. 2008;14(33):5125-5132.

103. Duijvestein M, Vos AC, Roelofs H, et al. Autologous bone marrowderived mesenchymal stromal cell treatment for refractory luminal Crohn's disease: results of a phase I study. Gut. 2010;59(12): 1662-1669.

104. Srivastava AS, Feng Z, Mishra R, Malhotra R, Kim HS, Carrier E. Embryonic stem cells ameliorate piroxicam-induced colitis in IL10-/KO mice. Biochem Biophys Res Commun. 2007;361(4):953-959.

105. Zhou Q, Price DD, Dreher KL, et al. Localized colonic stem cell transplantation enhances tissue regeneration in murine colitis. $J$ Cell Mol Med. 2012;16(8):1900-1915.
106. Hayashi Y, Tsuji S, Tsujii M, et al. The transdifferentiation of bonemarrow-derived cells in colonic mucosal regeneration after dextransulfate-sodium-induced colitis in mice. Pharmacology. 2007;80(4): 193-199.

107. Godoi DF, Cardoso CR, Silva MJ, et al. Reappraisal of total body irradiation followed by bone marrow transplantation as a therapy for inflammatory bowel disease. Immunobiology. 2013;218(3):317-324.

108. He XW, He XS, Lian L, Wu XJ, Lan P. Systemic infusion of bone marrow-derived mesenchymal stem cells for treatment of experimental colitis in mice. Dig Dis Sci. 2012;57(12):3136-3144.

109. Akiyama K, Chen C, Wang D, et al. Mesenchymal-stem-cell-induced immunoregulation involves Fas-ligand-/Fas-mediated T cell apoptosis. Cell Stem Cell. 2012;10(5):544-555.

110. Tanaka F, Tominaga K, Ochi M, et al. Exogenous administration of mesenchymal stem cells ameliorates dextran sulfate sodium-induced colitis via anti-inflammatory action in damaged tissue in rats. Life Sci. 2008;83(23-24):771-779.

111. Hayashi Y, Tsuji S, Tsujii M, et al. Topical implantation of mesenchymal stem cells has beneficial effects on healing of experimental colitis in rats. J Pharmacol Exp Ther. 2008;326(2):523-531.

112. Claes IJ, De Keersmaecker SC, Vanderleyden J, Lebeer S. Lessons from probiotic-host interaction studies in murine models of experimental colitis. Mol Nutr Food Res. 2011;55(10):1441-1453.

113. Bennet JD, Brinkman M. Treatment of ulcerative colitis by implantation of normal colonic flora. Lancet. 1989;1(8630):164.

114. Couturier-Maillard A, Secher T, Rehman A, et al. NOD2-mediated dysbiosis predisposes mice to transmissible colitis and colorectal cancer. J Clin Invest. 2013;123(2):700-711.

115. Kahn SA, Vachon A, Rodriquez D, et al. Patient perceptions of fecal microbiota transplantation for ulcerative colitis. Inflamm Bowel Dis. 2013;19(7):1506-1513.

116. Ng SC, Lam YT, Tsoi KK, Chan FK, Sung JJ, Wu JC. Systematic review: the efficacy of herbal therapy in inflammatory bowel disease. Aliment Pharmacol Ther. 2013;38(8):854-863.

117. Ke F, Yadav PK, Ju LZ. Herbal medicine in the treatment of ulcerative colitis. Saudi J Gastroenterol. 2012;18(1):3-10.

118. Langmead L, Feakins RM, Goldthorpe S, et al. Randomized, doubleblind, placebo-controlled trial of oral aloe vera gel for active ulcerative colitis. Aliment Pharmacol Ther. 2004;19(7):739-747.

119. Ben-Arye E, Goldin E, Wengrower D, Stamper A, Kohn R, Berry E. Wheat grass juice in the treatment of active distal ulcerative colitis: a randomized double-blind placebo-controlled trial. Scand J Gastroenterol. 2002;37(4):444-449.

120. Tang T, Targan SR, Li ZS, Xu C, Byers VS, Sandborn WJ. Randomised clinical trial: herbal extract HMPL-004 in active ulcerative colitis - a double-blind comparison with sustained release mesalazine. Aliment Pharmacol Ther. 2011;33(2):194-202.

121. Langhorst J, Varnhagen I, Schneider SB, et al. Randomised clinical trial: a herbal preparation of myrrh, chamomile and coffee charcoal compared with mesalazine in maintaining remission in ulcerative colitis: a double-blind, double-dummy study. Aliment Pharmacol Ther. 2013;38(5):490-500.

122. Hanai $\mathrm{H}$, Iida $\mathrm{T}$, Takeuchi $\mathrm{K}$, et al. Curcumin maintenance therapy for ulcerative colitis: randomized, multicenter, double-blind, placebocontrolled trial. Clin Gastroenterol Hepatol. 2006;4(12):1502-1506.

123. Michelsen KS, Wong MH, Ko B, Thomas LS, Dhall D, Targan SR. HMPL-004 (Andrographis paniculata extract) prevents development of murine colitis by inhibiting T-cell proliferation and TH1/TH17 responses. Inflamm Bowel Dis. 2013;19(1):151-164. 


\section{Publish your work in this journal}

Drug Design, Development and Therapy is an international, peerreviewed open-access journal that spans the spectrum of drug design and development through to clinical applications. Clinical outcomes, patient safety, and programs for the development and effective, safe, and sustained use of medicines are a feature of the journal, which has also been accepted for indexing on PubMed Central. The manuscript management system is completely online and includes a very quick and fair peer-review system, which is all easy to use. Visit http://www.dovepress.com/testimonials.php to read real quotes from published authors.

Submit your manuscript here: http://www.dovepress.com/drug-design-development-and-therapy-journal 